\title{
The Decomposition of Metastable $\beta$-phase Titanium Alloys
}

\author{
By S. Hanada* and O. Izumi*
}

\begin{abstract}
The crystallography and morphology of quenched and aged metastable $\beta$-phase titanium alloys, $\mathrm{Ti}-15 \mathrm{Mo}-5 \mathrm{Zr}$ and $\mathrm{Ti}-15 \mathrm{Mo}-5 \mathrm{Zr}-3 \mathrm{Al}$, were studied by transmission electron microscopy. In both alloys it was observed that there were two types of the $\alpha$ phase, Type $1 \alpha$ (obeying the well-known Burgers orientation relation between $\alpha$ and $\beta$ phases) and Type $2 \alpha$ (not obeying the Burgers relation). Moreover, two types of $\alpha$ phase morphology were revealed: one is plate or needle-like and the other is raft-like. The precipitation sequence of Type $1 \alpha \rightarrow$ Type $2 \alpha$ was confirmed in the Ti-15Mo-5Zr-3Al alloy aged at 773 and $623 \mathrm{~K}$. The morphology of the Type $2 \alpha$ is platelike. The $\omega \rightarrow 2 \alpha$ transition was observed in the $\mathrm{Ti}-15 \mathrm{Mo}-5 \mathrm{Zr}$ alloy aged at $673 \mathrm{~K}$. The morphology of the Type $2 \alpha$ is raft-like. The $\omega$, Type $1 \alpha$ and Type $2 \alpha$ with platelet morphology were formed in the $\mathrm{Ti}-15 \mathrm{Mo}-5 \mathrm{Zr}$ alloy aged at $748 \mathrm{~K}$. The effect of the crystallography and morphology of the precipitates on the mechanical properties is discussed in comparison with other metastable $\beta$-titanium alloys.
\end{abstract}

(Received November 21, 1979)

\section{Introduction}

Recently, Ohtani et al..$^{(1) \sim(5)}$ have found that metastable beta $(\beta)$ titanium alloys, Ti$15 \mathrm{Mo}-5 \mathrm{Zr}$ and $\mathrm{Ti}-15 \mathrm{Mo}-5 \mathrm{Zr}-3 \mathrm{Al}$ alloys, are excellent in corrosion resistance, fabricability, weldability and strength-to-weight ratio. These alloys also have the advantage of being strengthened to very high levels by precipitation of alpha $(\alpha)$ and omega $(\omega)$ phase in a bcc $\beta$ matrix. Nishimura et al. ${ }^{(6)}$ have demonstrated the optimum heat-treatment conditions and discussed the relation between the mechanical properties and the precipitation phases determined from the X-ray diffraction results. According to their results, the precipitation of the $\omega$ and $\alpha$ phases is controlled sensitively by the aging conditions and therefore, the mechanical properties are complicatedly affected by the aging conditions.

In addition, two types of $\alpha$ phase precipitate have recently been shown to form during aging $^{(7)(8)}$. One is the well known "Burgers $\alpha^{\text {"(9) }}$ (Type $1 \alpha$ ), while the other does not obey the Burgers orientation relation and has been designated Type $2 \alpha$. Type $2 \alpha$ is assumed to be more stable than Type $1 \alpha$.

The purpose of this paper is to observe the

* The Research Institute for Iron, Steel and Other Metals, Tohoku University, Sendai 980, Japan.

Trans. JIM precipitates by using a transmission electron microscope and to investigate the crystallography and morphology of the $\omega$ and $\alpha$ phases in $\mathrm{Ti}-15 \mathrm{Mo}-5 \mathrm{Zr}$ and $\mathrm{Ti}-15 \mathrm{Mo}-5 \mathrm{Zr}-$ $3 \mathrm{Al}$ alloys and moreover to discuss the characteristics of the decomposition and mechanical properties in metastable $\beta$-titanium alloys.

\section{Experimental}

The material for this investigation, generously supplied by Kobe Steel, Ltd., had a nominal composition of $\mathrm{Ti}-15 \mathrm{Mo}-5 \mathrm{Zr}$ and $\mathrm{Ti}-15 \mathrm{Mo}-$ $5 \mathrm{Zr}-3 \mathrm{Al}$. The material was received in the form of a $15 \mathrm{~mm}$ diameter rod. The actual composition determined by chemical analysis is given in Table 1.

The material was swaged to $10 \mathrm{~mm}$ diameter. These rods were solution heat-treated in argon atmosphere at $1003 \mathrm{~K}$ for $3.6 \mathrm{ks}$ (Ti-15Mo$5 \mathrm{Zr})$ and at $1058 \mathrm{~K}$ for $3.6 \mathrm{ks}(\mathrm{Ti}-15 \mathrm{Mo}-5 \mathrm{Zr}-$ $3 \mathrm{Al})$ then water-quenched. After the rods were mechanically machined to $4.5 \mathrm{~mm}$ diameter, the rods were put into evacuated quartz capsules and aged at low temperatures. The sample preparation and heat-treatment methods described above are almost the same as those of the paper reported by Nishimura et al. ${ }^{(6)}$

Discs with about $3 \mathrm{~mm}$ diameter and $0.3 \mathrm{~mm}$ thickness were spark cut from a central part of the heat-treated rods. Thin foils were prepared from these discs using standard electropolishing

1980 Vol. 21 


\section{S. Hanada and O. Izumi}

Table 1 The chemical composition of $\mathrm{Ti}-15 \mathrm{Mo}-5 \mathrm{Zr}$ and $\mathrm{Ti}-15 \mathrm{Mo}-5 \mathrm{Zr}-3 \mathrm{Al}$ in wt $\%$.

\begin{tabular}{lccccccc}
\hline & Mo & $\mathrm{Zr}$ & $\mathrm{Al}$ & $\mathrm{Fe}$ & $\mathrm{C}$ & $\mathrm{O}$ & $\mathrm{N}$ \\
\hline $\mathrm{Ti}-15 \mathrm{Mo}-5 \mathrm{Zr}$ & 14.97 & 5.04 & 2.93 & 0.043 & 0.006 & 0.165 & 0.0129 \\
$\mathrm{Ti}-15 \mathrm{Mo}-5 \mathrm{Zr}-3 \mathrm{Al}$ & 14.74 & 4.76 & - & 0.046 & 0.008 & 0.183 & 0.0058 \\
\hline \hline
\end{tabular}
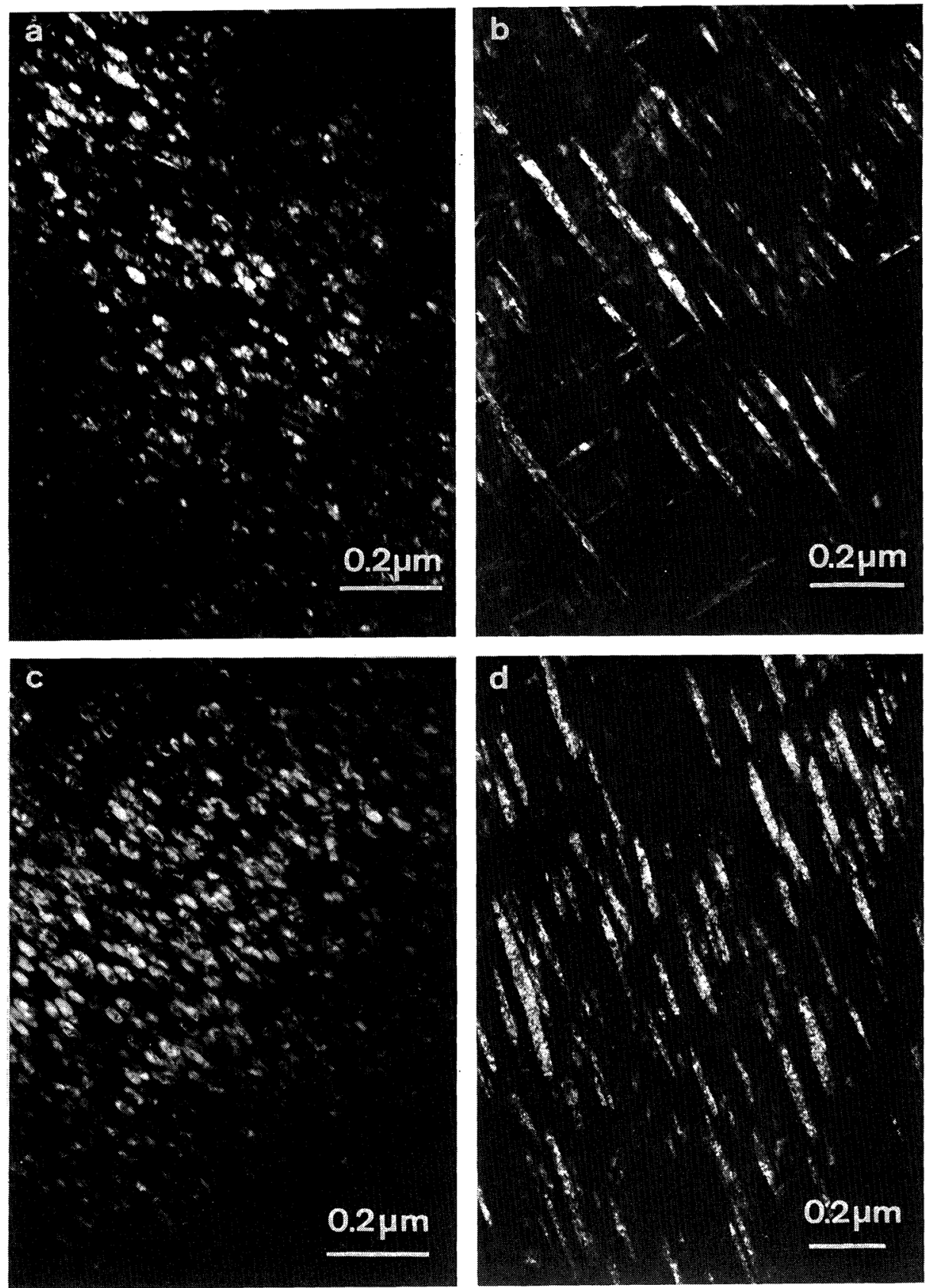

Photo. 1 Dark field electron micrographs of Ti-15Mo-5Zr aged at $748 \mathrm{~K}$ for $1.2 \mathrm{ks}$ (a), $6 \mathrm{ks}$ (b) and $60 \mathrm{ks}(\mathrm{c}),(\mathrm{d})$. 
techniques $^{(10)}$. A JEOL 200 B electron microscope equipped with a double-tilt goniometer stage was used at $200 \mathrm{kV}$.

\section{Results}

\section{Ti-15Mo-5Zr}

The optimum heat-treatment condition for a $\mathrm{Ti}-15 \mathrm{Mo}-5 \mathrm{Zr}$ alloy to give the excellent tensile properties was reported to be aging at $748 \mathrm{~K}$ for $6 \mathrm{ks}$ after solutionizing at $1003 \mathrm{~K}$ for $3.6 \mathrm{ks}$ and water-quenching ${ }^{(6)}$. In the aging transformation diagram determined from Xray diffraction results ${ }^{(6)}$, only the $\omega$ phase is expected to precipitate during aging at $573 \mathrm{~K}$, while the $\alpha$ phase may appear in the $(\beta+\omega)$ phase during aging at $673 \mathrm{~K}$ for a longer period than $300 \mathrm{ks}$. Therefore, in the present work, three aging temperatures, 748,673 and $573 \mathrm{~K}$,
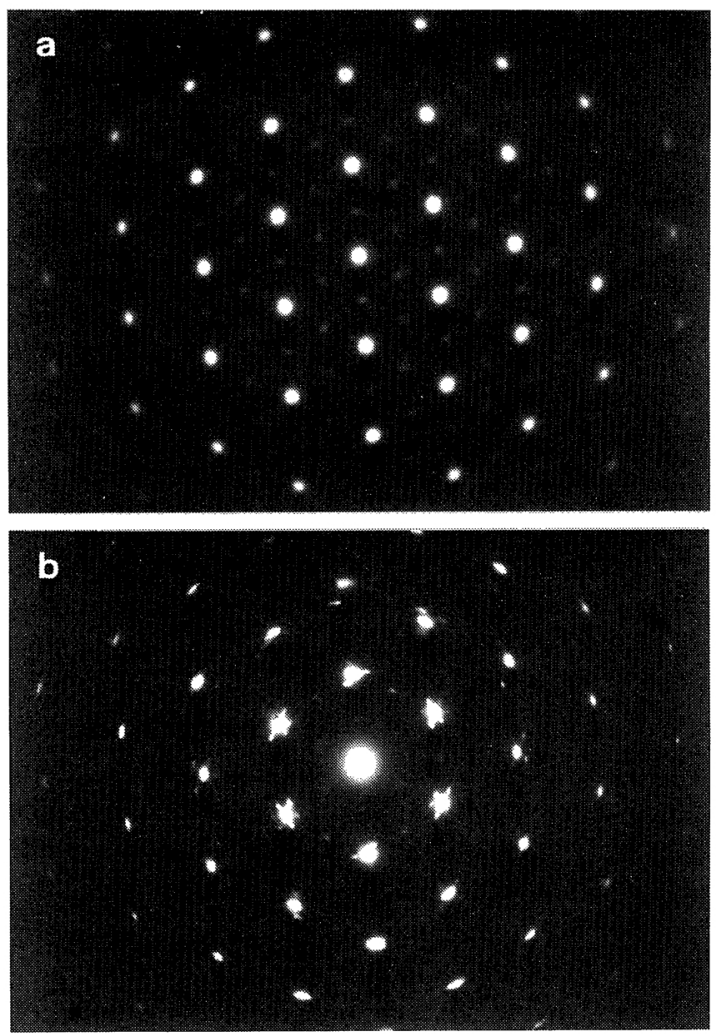

Photo. $2 \mathrm{Ti}-15 \mathrm{Mo}-5 \mathrm{Zr}$ aged at $748 \mathrm{~K}$ for $6 \mathrm{ks}$. Electron diffraction patterns demonstrating existence of Type $1 \alpha$-phase (a) and coexistence of Type $1 \alpha$ and Type $2 \alpha$-phase (b). Zone normal $=\langle 111\rangle_{\beta}$. were selected to investigate the morphology and crystallography of precipitates in a $\mathrm{Ti}-$ $15 \mathrm{Mo}-5 \mathrm{Zr}$ alloy.

Photograph 1 shows dark field electron micrographs of a $\mathrm{Ti}-15 \mathrm{Mo}-5 \mathrm{Zr}$ alloy aged at $748 \mathrm{~K}$. Photograph 1(a) shows the $\omega$ phase formation in this alloy aged at $748 \mathrm{~K}$ for 1.2 ks. In other areas very thin platelike precipitates with a low density were observed. On aging at $748 \mathrm{~K}$ for $6 \mathrm{ks}$, the $\alpha$ phase becomes visible, Photo. 1(b). Upon continued aging, the $\alpha$ phase appears frequently, but the $\omega$ phase is rarely observed in a very restricted area of a foil, Photo. 1(c) and (d). However, the cause for formation of the $\omega$ phase of high density in the restricted area as shown in Photo. 1(c) is uncertain at present. Electron diffraction patterns under this aging condition is shown in Photo. 2 which were taken from the same foil but different selected area. Photograph 2(a) demonstrates the existence of Type $1 \alpha$ phase and Photo. 2(b) shows the co-existence of Types $1 \alpha$ and $2 \alpha$ phases. After prolonged aging at $748 \mathrm{~K}$ for $300 \mathrm{ks}$, the $\alpha$ phase develops considerably (Photo. 3 ), while the $\omega$ phase disappeared.

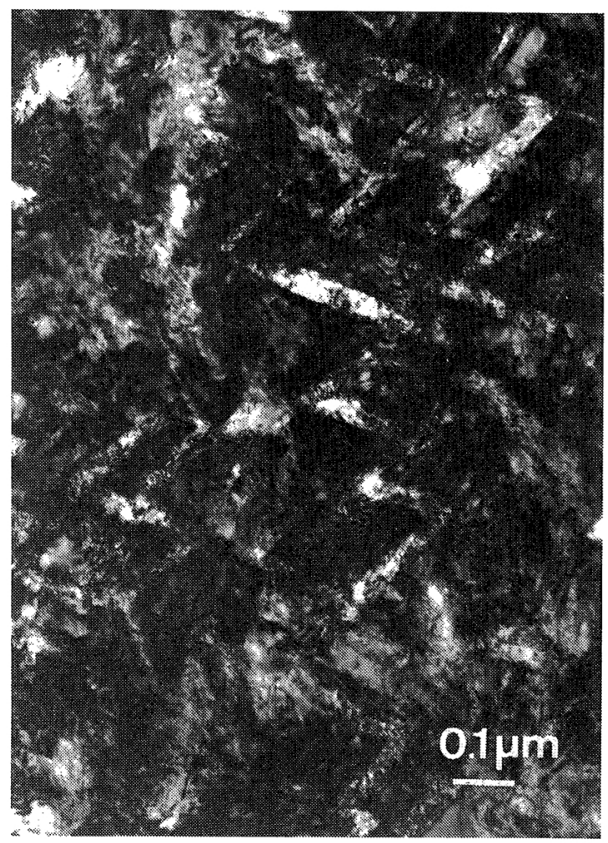

Photo. 3 A bright field electron micrograph of Ti-15Mo-5Zr aged at $748 \mathrm{~K}$ for $300 \mathrm{ks}$. 

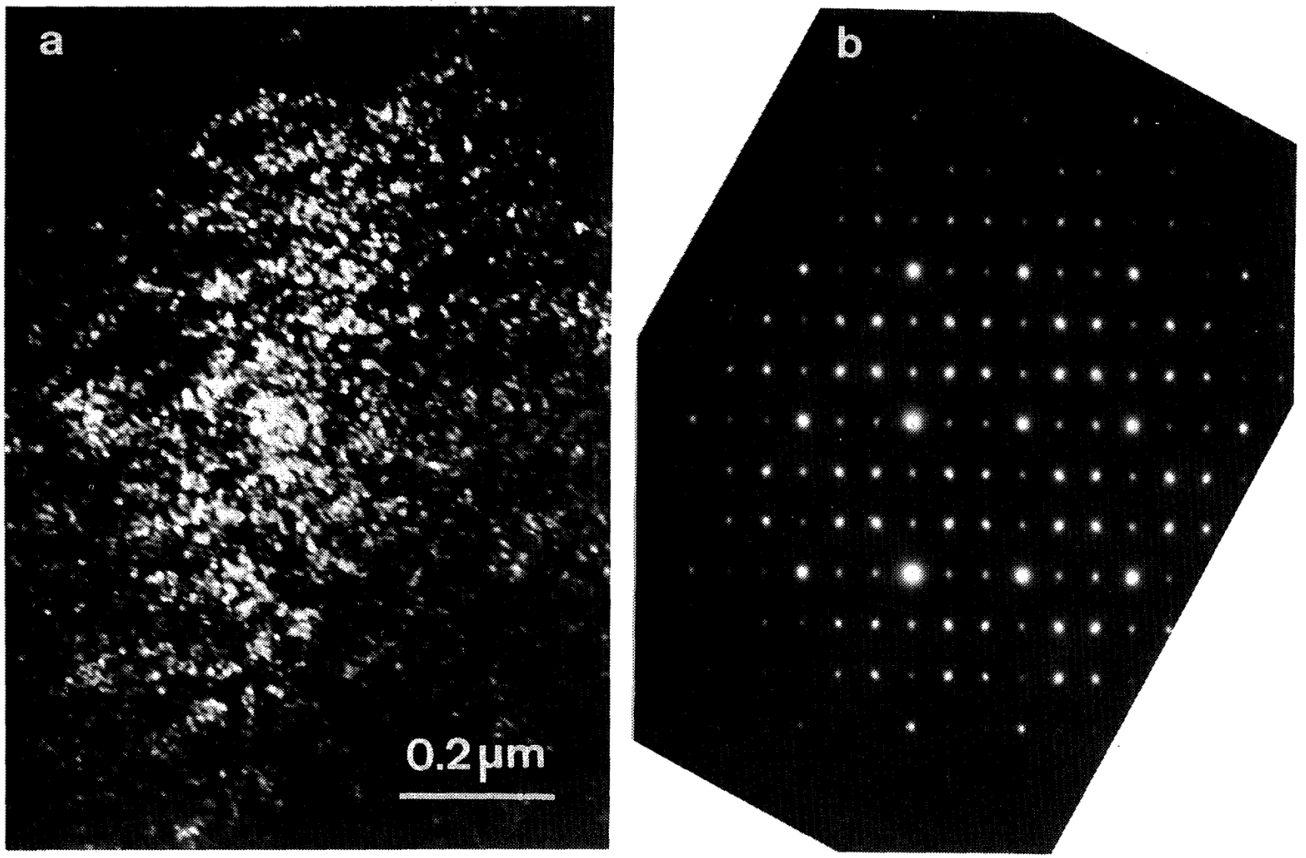

Photo. $4 \mathrm{Ti}-15 \mathrm{Mo}-5 \mathrm{Zr}$ aged at $673 \mathrm{~K}$ for $1.2 \mathrm{ks}$. (a) a dark field electron micrograph illustrating $\omega$-phase; (b) an electron diffraction pattern. Zone normal $=\langle 110\rangle_{\beta}$.

Photograph 4 shows a dark field electron micrograph illustrating $\omega$ phase and an electron diffraction pattern of a Ti-15Mo-5Zr alloy aged at $673 \mathrm{~K}$ for $1.2 \mathrm{ks}$. The particle size of the $\omega$ phase formed on aging at $673 \mathrm{~K}$ (Photo. 4) is smaller than that on aging at $748 \mathrm{~K}$ (Photo. $1(\mathrm{a})$ and (c)). Formation of the $\alpha$ phase was not detected. With increasing aging time at $673 \mathrm{~K}$, the electron diffraction pattern changes remarkably, Photo. 5. The arcing of the precipitate reflections shown in Photo. 5 indicates that the $\alpha$ phase is Type $2 \alpha$. The electron diffraction pattern after aging at $673 \mathrm{~K}$ for $300 \mathrm{ks}$ was similar to that of Photo. 5. The morphology of the $\alpha$ phase producing the arcing is revealed to be a large number of particles with nonuniform shapes as shown in the dark field micrograph, Photo. 6.

Photograph 7 shows the electron diffraction patterns of a $\mathrm{Ti}-15 \mathrm{Mo}-5 \mathrm{Zr}$ alloy solutionized and aged at $573 \mathrm{~K}$. The weak reflections of athermally formed $\omega$ phase with diffuse streaking are observed after solutionization, Photo. 7(a). The $\omega$ phase reflections become sharp during aging, while the diffuse streaking disappears, Photo. 7(b) (d). The dark field electron micrographs illustrating the $\omega$ phase are presented in Photo. 8. With increasing aging time, no apparent change is observed in the density and the size of $\omega$ particles.

\section{Ti-15Mo-5Zr-3Al}

The optimum heat treatment condition to obtain the good tensile properties in a $\mathrm{Ti}_{-}$ $15 \mathrm{Mo}-5 \mathrm{Zr}-3 \mathrm{Al}$ alloy is aging at $773 \mathrm{~K}$ for $60 \mathrm{ks}$ after solutionizing at $1058 \mathrm{~K}$ for $3.6 \mathrm{ks}$ and water quenching ${ }^{(6)}$. Therefore, the precipitation process of a $\mathrm{Ti}-15 \mathrm{Mo}-5 \mathrm{Zr}-3 \mathrm{Al}$ alloy aged at $773 \mathrm{~K}$ was examined. As seen in Photos. 9 and 10, at the initial stage of precipitation, the Type $1 \alpha$-phase precipitates in the form of platelets. With increasing aging time, the diffraction evidence from these samples shows that both types of precipitates, $1 \alpha$ and $2 \alpha$, are present. On further aging the $\alpha$ phase coalesces into plates or needles in agreement with previous work $^{(11) \sim(13)}$, Photo. 11.

It is known that the addition of aluminum suppresses $\omega$ phase formation. In order to investigate the effect of small aluminum addition on the crystallography and morphology of $\omega$ phase, another aging temperature 

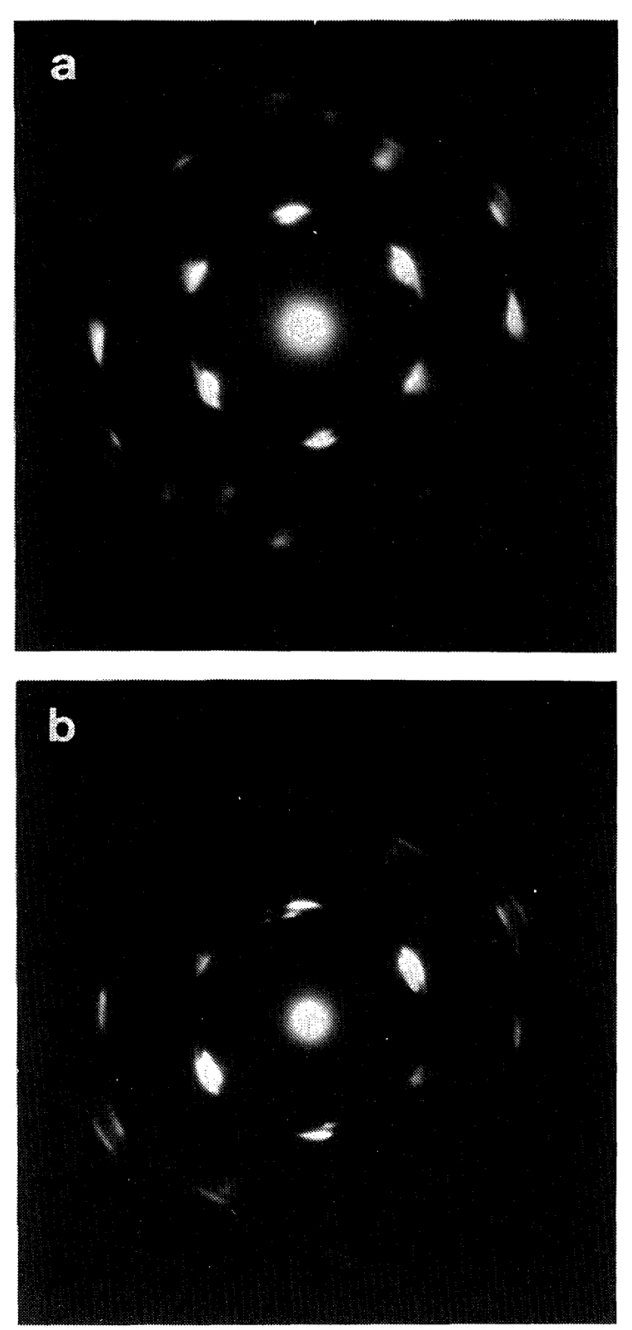

Photo. 5 Electron diffraction patterns of Ti-15Mo$5 \mathrm{Zr}$ aged at $673 \mathrm{~K}$ for $6 \mathrm{ks}$ (a) and $60 \mathrm{ks}$ (b). Zone normal $=\langle 111\rangle_{\beta}$.

$623 \mathrm{~K}$ was selected on the basis of the aging transformation diagram for $\mathrm{Ti}-15 \mathrm{Mo}-5 \mathrm{Zr}-$ $3 \mathrm{Al}^{(6)}$. However, even after prolonged aging at $623 \mathrm{~K}$ no evidence of $\omega$ phase formation was found but the $\alpha$ phase was clearly recognized. These results are shown in Photos. 12 and 13. It is apparent from the comparison with Photo. 12(a) that after aging at $623 \mathrm{~K}$ for $300 \mathrm{ks}$ Type $1 \alpha$ phase is seen significantly in a diffraction pattern of Photo. 12(b), where the $\alpha$ reflections show streaking, which is due to very thin $\alpha$ platelets. On further aging the streaked Type $1 \alpha$ reflections changes into the spotted Type $1 \alpha$ reflections (Photo. 12(c)). In addition extra spots and streaking around $b c c$ reflections in the $\{111\}_{\beta}$ selected area diffraction pattern appear. It is likely in comparison with Photo. 10(b) that these reflections correspond with the initial stage of Type $2 \alpha$ phase precipitation. Photograph 13 shows the morphology of the $\alpha$ precipitates in a $\mathrm{Ti}-15 \mathrm{Mo}-5 \mathrm{Zr}-3 \mathrm{Al}$ alloy aged at $623 \mathrm{~K}$ for $1.2 \mathrm{Ms}$. The $\alpha$ phase begins to coalesce into plates or needles.

\section{Discussion}

\section{Crystallography and morphology}

Rhodes and Williams have first shown that there are two types of $\alpha$ phase which precipitate from the $\beta$ phase during aging in $\mathrm{Ti}-14 \% \mathrm{Mo}-$ $6 \% \mathrm{Al}$ and $\mathrm{Ti}-11.6 \% \mathrm{Mo}$ alloys ${ }^{(7)}$. They assumed that Type $2 \alpha$ phase would be more stable than Type $1 \alpha$ on the basis of the observations that Type $1 \alpha$ formed initially and Type $2 \alpha$ formed after longer aging period and/or at higher aging temperatures. Their assumption seems to be confirmed by the results obtained by Rhodes and Paton in Ti-3Al-8V-6Cr-4Mo$4 \mathrm{Zr}$ (Beta-C) ${ }^{(8)}$. They observed Type $1 \alpha$ phase in the alloy aged at $773 \mathrm{~K}$ for $7.2 \mathrm{ks}$, although the initial reaction in the precipitation process at $773 \mathrm{~K}$ was the phase separation $\beta \rightarrow \beta+\beta^{\prime}$. Type $1 \alpha$ phase disappeared and Type $2 \alpha$ appeared after more than $14.4 \mathrm{ks}$ aging at $773 \mathrm{~K}$.

This precipitation sequence of $\beta \rightarrow \beta+$ Type $1 \alpha \rightarrow \beta+$ Type $2 \alpha$ was also observed in the present experiments when the $\alpha$ phase precipitates directly from the $\beta$ without $\omega$ phase precipitation. The typical result was obtained in a $\mathrm{Ti}-15 \mathrm{Mo}-5 \mathrm{Zr}-3 \mathrm{Al}$ aged at $773 \mathrm{~K}$ (Photo. 10), where the type $1 \alpha$ reflections first appear and on further aging they become very weak compared with the type $2 \alpha$ reflections. This trend seems to be also observed in the same alloy aged at $623 \mathrm{~K}$ (Photo. 12).

Williams et al. have observed the Type $1 \alpha$ phase with streaked reflections at the initial stage of aging in $\mathrm{Ti}-20 \% \mathrm{~V}-3 \% \mathrm{Al}^{(14)}$. The diffraction pattern presented by them is quite similar to that of Photo. 12(b). Paris et al. have observed Type $2 \alpha$ phase platelets in an 

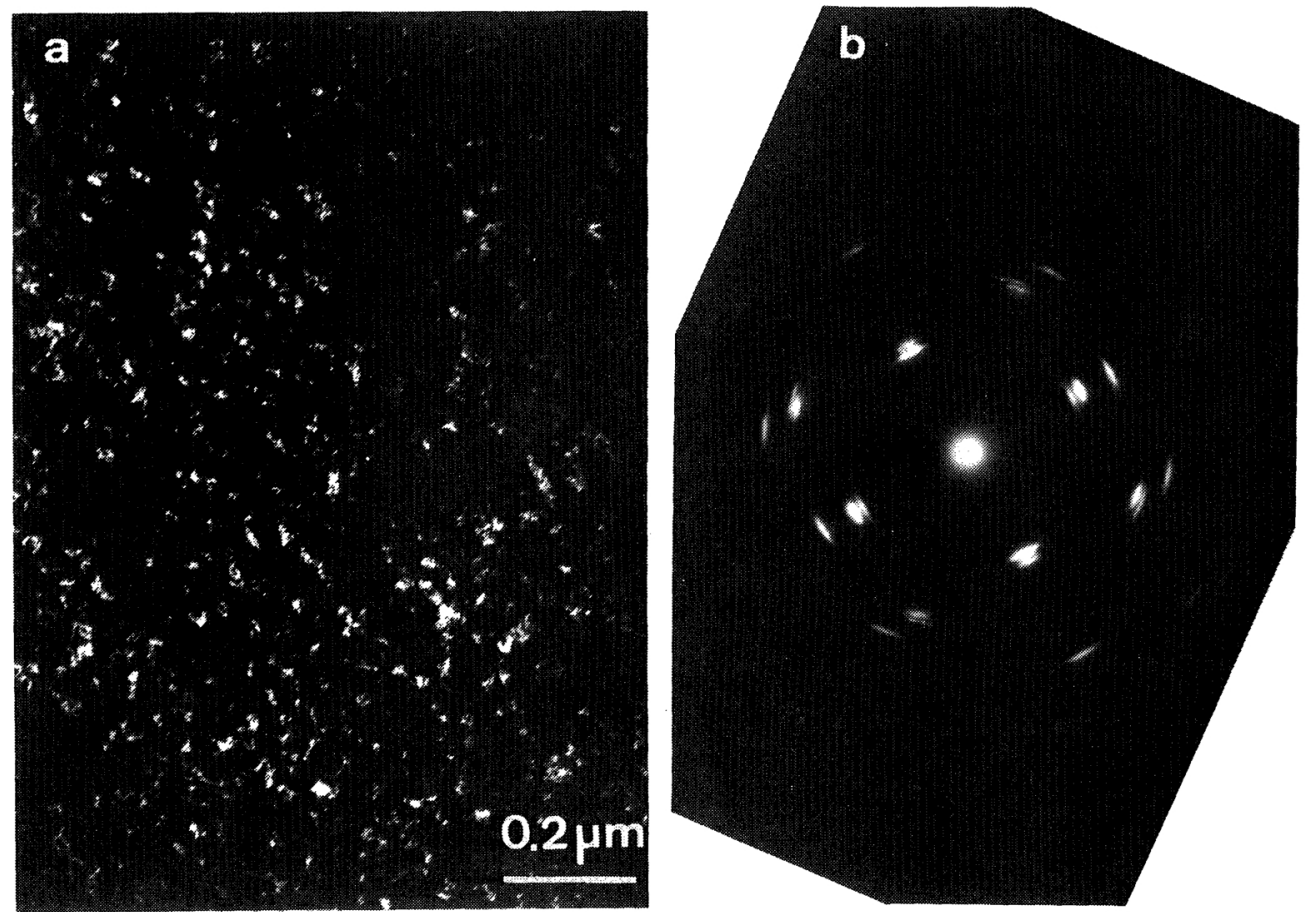

Photo. $6 \mathrm{Ti}-15 \mathrm{Mo}-5 \mathrm{Zr}$ aged at $673 \mathrm{~K}$ for $300 \mathrm{ks}$. (a) a dark field electron micrograph illustrating $2 \alpha$-phase; (b) an electron diffraction pattern. Zone normal $=\langle 100\rangle_{\beta}$.
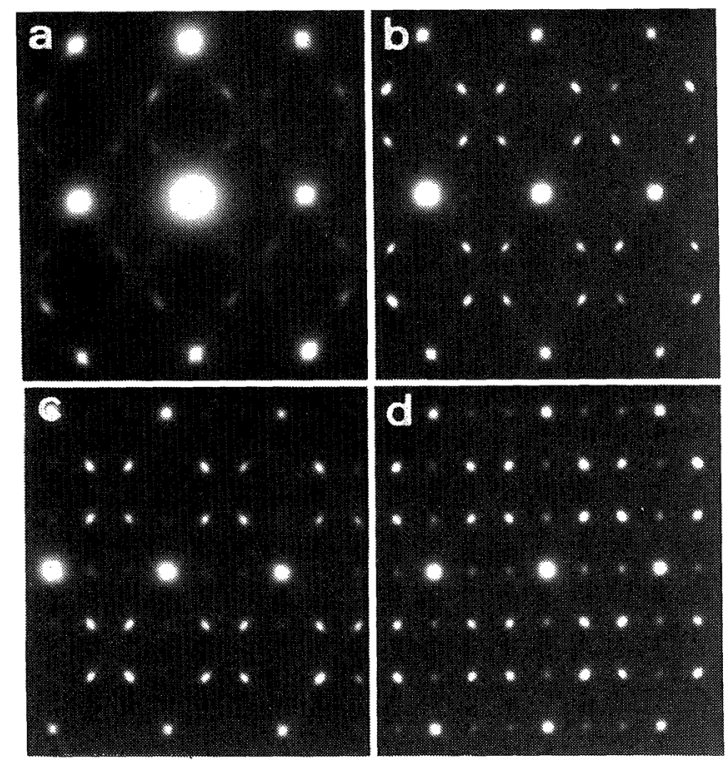

Photo. 7 Electron diffraction patterns of Ti-15Mo$5 \mathrm{Zr}$ solutionized (a) and aged at $573 \mathrm{~K}$ for $1.2 \mathrm{ks}$ (b), $6 \mathrm{ks}$ (c), and $300 \mathrm{ks}$ (d). Zone normal $=\langle 110\rangle_{\beta}$. aged $\mathrm{Ti}-24 \% \mathrm{~V}$ alloy ${ }^{(13)}$.

Therefore, the $\beta \rightarrow \beta+$ Type $1 \alpha \rightarrow \beta+$ Type $2 \alpha$ sequence may generally be expectable in metastable $\beta$-titanium alloys when the $\omega$ phase is not formed on aging, although no experimental work by electron microscopic observation has been reported in alloys other than those described above.

The precipitation process in a $\mathrm{Ti}-15 \mathrm{Mo}-5 \mathrm{Zr}$ alloy is different from that of a $\mathrm{Ti}-15 \mathrm{Mo}-5 \mathrm{Zr}-$ $3 \mathrm{Al}$ alloy, since the $\omega$ phase forms in the former alloy. The most remarkable difference can be seen in the precipitation process at $673 \mathrm{~K}$. The formed phase was Type $2 \alpha$ instead of $\omega$ after $6 \mathrm{ks}$ aging, while Type $1 \alpha$ phase was not observed. The morphology of Type $2 \alpha$ phase is like "rafts" of nonuniform shape containing a large number of particles. The present observation is in contrast to the results that the morphology of Type $2 \alpha$-phase which forms from Type $1 \alpha$ or simultaneously with Type $1 \alpha$ is generally plate- or needle-like ${ }^{(7)(8)}$. However, it is interesting to compare this observation with the results of Beta-C. That is, in Beta-C two 

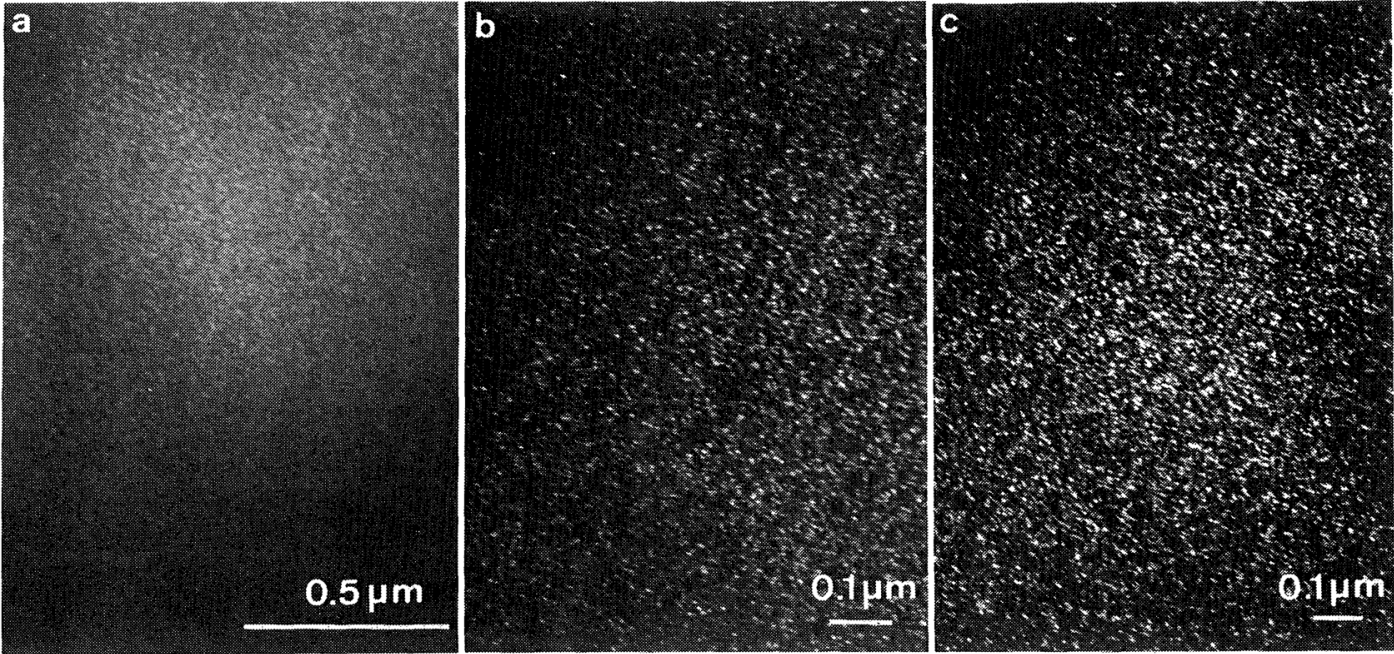

Photo. 8 Dark field electron micrographs illustrating $\omega$-phase of Ti-15Mo-5Zr aged at $573 \mathrm{~K}$ for $1.2 \mathrm{ks}(\mathrm{a}), 6 \mathrm{ks}$ (b) and $300 \mathrm{ks}$ (c).
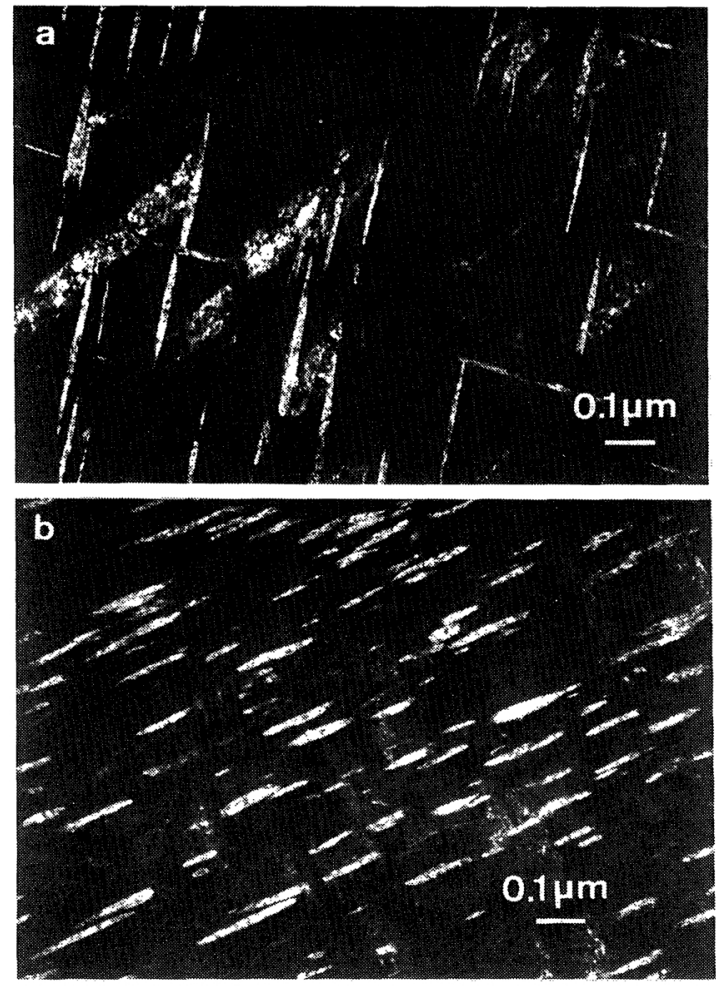

Photo. 9 Dark field electron micrographs of $\mathrm{Ti}-$ $15 \mathrm{Mo}-5 \mathrm{Zr}-3 \mathrm{Al}$ aged at $773 \mathrm{~K}$ for $1.2 \mathrm{ks}$ (a) and $6 \mathrm{ks}(\mathrm{b})$.
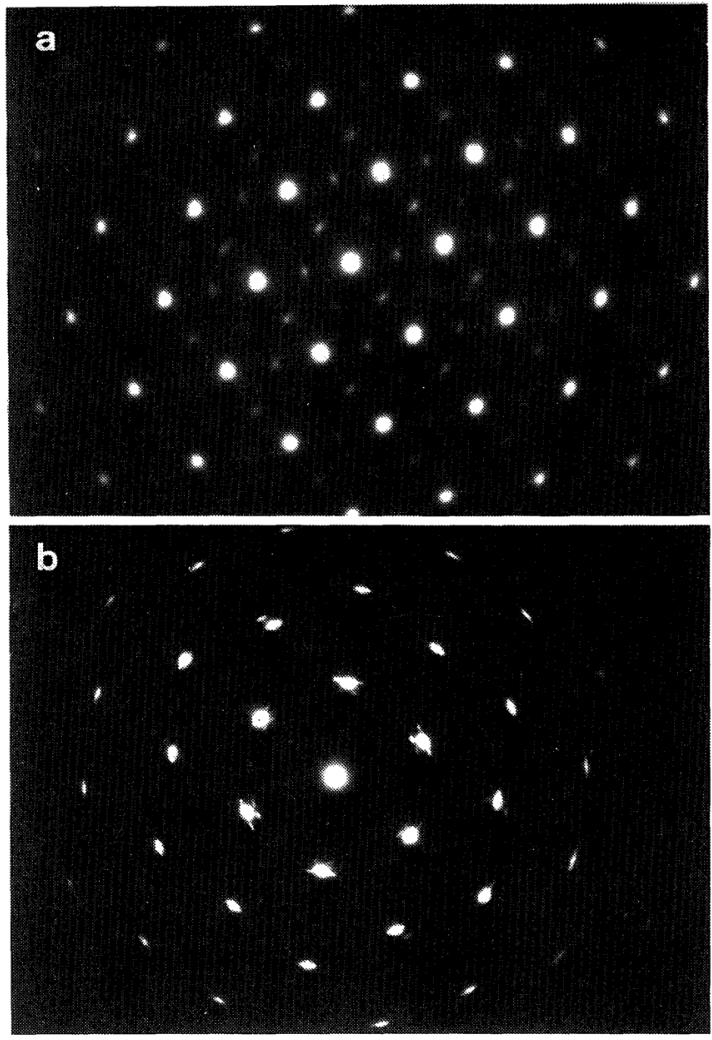

Photo. 10 Electron diffraction patterns of Ti-15Mo$5 \mathrm{Zr}-3 \mathrm{Al}$ aged at $773 \mathrm{~K}$ for $1.2 \mathrm{ks}$ (a) and $60 \mathrm{ks}$ (b). Zone normal $=\langle 111\rangle_{\beta}$. 

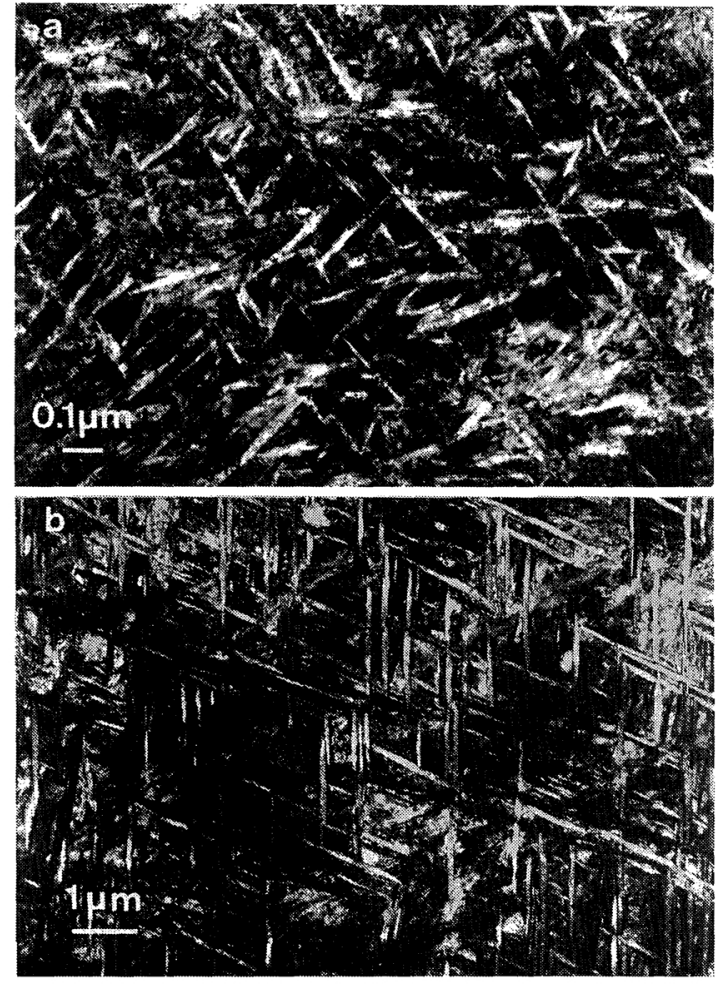

Photo. 11 Bright field electron micrographs of Ti-15Mo-5Zr-3Al aged at $773 \mathrm{~K}$ for $60 \mathrm{ks}$ (a) and $300 \mathrm{ks}$ (b).

kinds of $\beta^{\prime}$ in morphology are formed initially depending on aging temperature ${ }^{(8)}$. One is fine irregular shaped particles formed at low temperatures and the other is resolvable as discs lying on $\{100\}_{\beta}$ planes formed at high temperatures. On further aging, Type $2 \alpha$ rafts are formed at low temperature, while Type $2 \alpha$ platelets via Type $1 \alpha$ are formed at high temperature. Then it is apparent from the results of Beta-C, Ti-15Mo-5Zr and $\mathrm{Ti}-15 \mathrm{Mo}-5 \mathrm{Zr}-$ $3 \mathrm{Al}$ alloys that Type $2 \alpha$ rafts seem to be formed when fine particles, $\beta^{\prime}$ or $\omega$, are present in $\beta$ and moreover the subsequent aging temperature is low, and otherwise the formation of Type $1 \alpha$ or $2 \alpha$ platelets result in.

\section{Correlation of precipitates to tensile properties}

Tensile properties of $\mathrm{Ti}-15 \mathrm{Mo}-5 \mathrm{Zr}$ and $\mathrm{Ti}-$ $15 \mathrm{Mo}-5 \mathrm{Zr}-3 \mathrm{Al}$ have been investigated by Nishimura et al. in $\operatorname{detail}^{(6)}$. They have
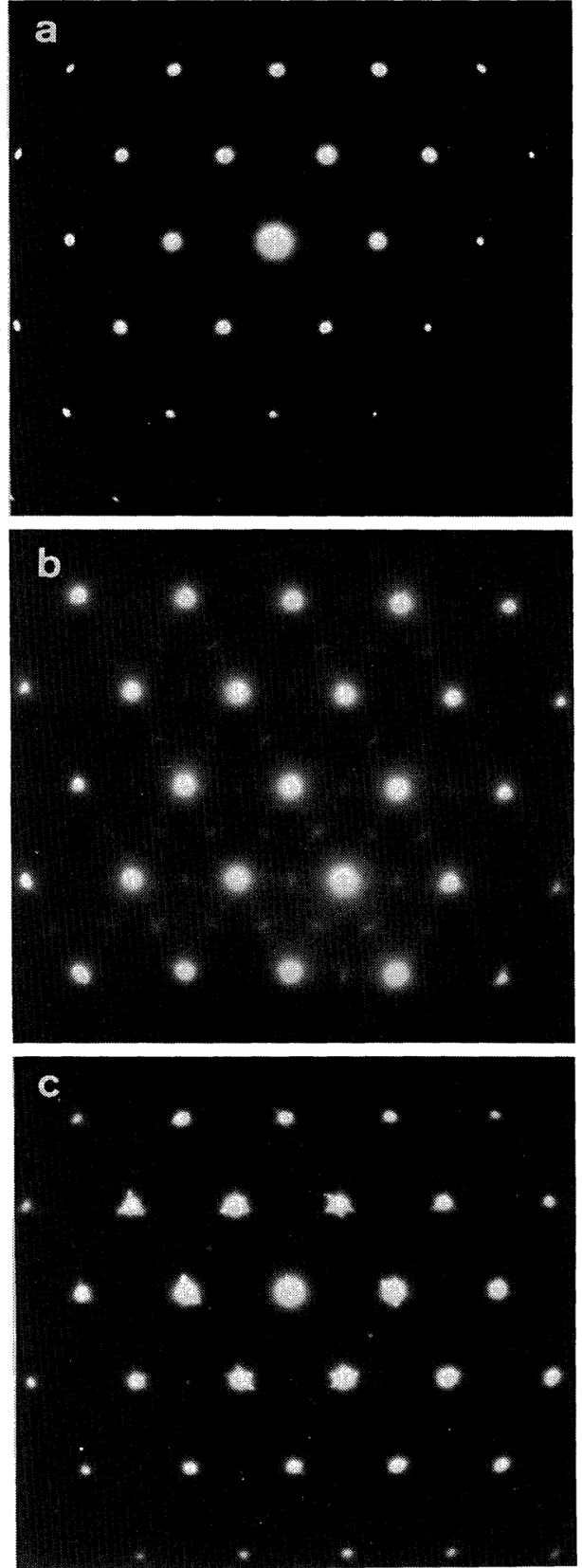

Photo. 12 Electron diffraction patterns of Ti-15Mo$5 \mathrm{Zr}-3 \mathrm{Al}$ solutionized (a) and aged at $623 \mathrm{~K}$ for 300 ks (b) and 1.2 Ms (c). Zone normal $=\langle 111\rangle_{\beta}$.

explained the strength under the optimum heattreatment conditions by considering properties of $\omega$ and $\alpha$ phases. That is, their explanation is based on the fact that the strength of the $\alpha$ phase in a $\mathrm{Ti}-15 \mathrm{Mo}-5 \mathrm{Zr}$ alloy is lower than 

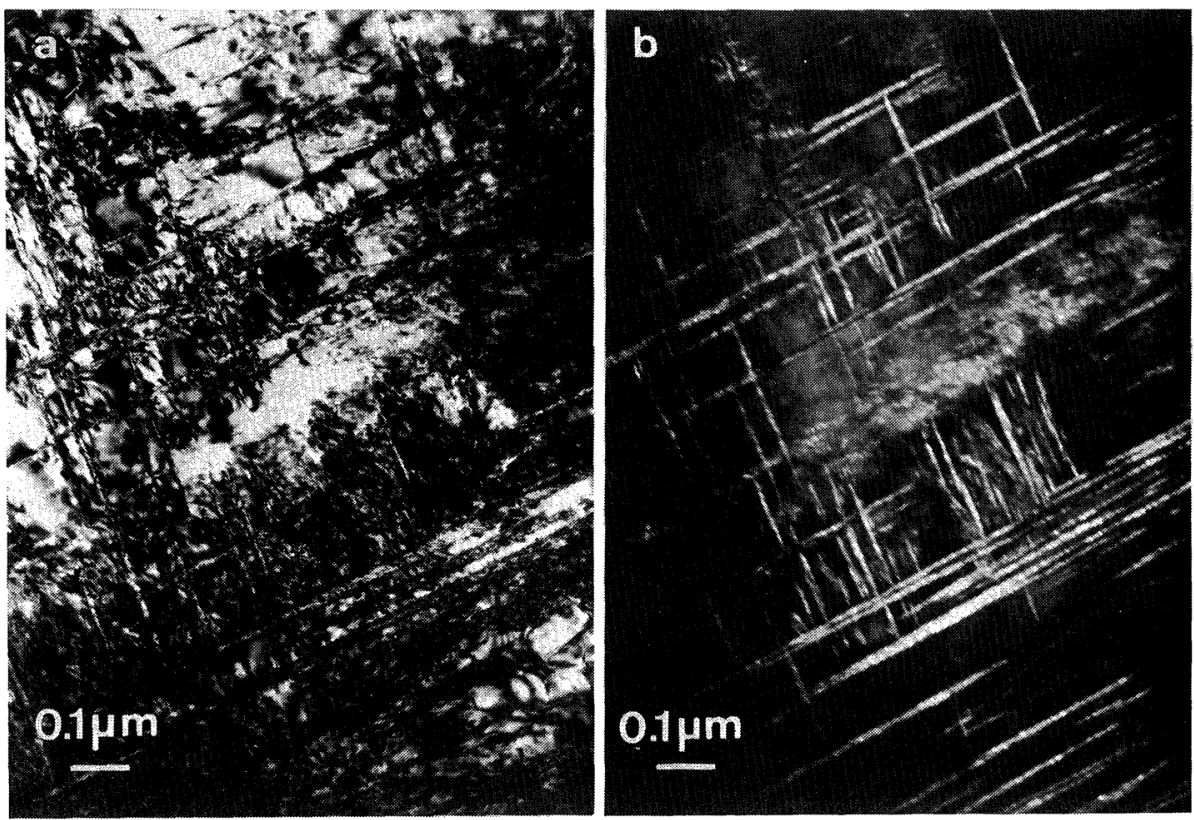

Photo. $13 \mathrm{Ti}-15 \mathrm{Mo}-5 \mathrm{Zr}-3 \mathrm{Al}$ aged at $623 \mathrm{~K}$ for $1.2 \mathrm{Ms}$. (a) a bright field and (b) a dark field electron micrograph.

that of the matrix, while the $\alpha$ phase in a $\mathrm{Ti}-$ $15 \mathrm{Mo}-5 \mathrm{Zr}-3 \mathrm{Al}$ alloy is highly strengthened by aluminum addition. In the current observations both Type $1 \alpha$ and $2 \alpha$ phases coexisted at the optimum aging temperatures for both alloys. Therefore, we could not discuss the effect of $1 \alpha$ and $2 \alpha$ phases on the tensile properties separately.

According to Nishimura et al., the embrittlement of $\mathrm{Ti}-15 \mathrm{Mo}-5 \mathrm{Zr}$ and $\mathrm{Ti}-15 \mathrm{Mo}-5 \mathrm{Zr}-$ $3 \mathrm{Al}$ alloys aged at low temperatures is due to the $\omega$ phase formation on the basis of the X-ray diffraction results ${ }^{(6)}$. But they could not explain the differences of ductilities between both alloys aged at low temperatures. However, we have observed Type $2 \alpha$ phase formation $\dagger$ on low temperature aging, e.g. in a Ti-15Mo$5 \mathrm{Zr}$ alloy aged at $673 \mathrm{~K}$ for $300 \mathrm{ks}$ and in a $\mathrm{Ti}-15 \mathrm{Mo}-5 \mathrm{Zr}-3 \mathrm{Al}$ alloy aged at $623 \mathrm{~K}$ for 1.2 Ms using an electron microscope. By considering the present electron microscopy results the differencies of ductilities described above

$\dagger$ Slight discrepancies are present in the precipitated phases determined by the X-ray diffraction ${ }^{(6)}$ and by the present electron microscopy in spite of the same aging conditions. The cause is uncertain at present. can be explained reasonably.

On prolonged aging of a Ti-15Mo- $5 \mathrm{Zr}$ alloy, Type $2 \alpha$ phase with "rafts" morphology was formed at $673 \mathrm{~K}$ and the $\omega$ phase was formed at $573 \mathrm{~K}$. These alloys were both embrittled remarkably ${ }^{(6)}$. On the other hand, the Ti$15 \mathrm{Mo}-5 \mathrm{Zr}-3 \mathrm{Al}$ alloy aged at $623 \mathrm{~K}$ for a long period was not so embrittled, although it was strengthened considerably ${ }^{(6)}$. Under this aging condition, Type $2 \alpha$ phase with platelike morphology was observed. Then it can be concluded from these results that embrittlement of a metastable $\beta$-Ti alloy aged at low temperatures is not always due to $\omega$ phase formation but is due to the formation of Type $2 \alpha$ phase with "rafts" morphology, which depends on aging condition. The same result that a metastable $\beta$-Ti alloy is embrittled by precipitation of Type $2 \alpha$ phase with "rafts" morphology has been reported in Beta-C aged at $623 \mathrm{~K}$ for a long time ${ }^{(8)}$. Therefore, the above observation should be very important for clarifying the mechanism of $\omega$ phase embrittlement, which will be discussed elsewhere.

On the contrary, a metastable $\beta$-Ti alloy is not embrittled significantly by the formation of the $\alpha$ phase with platelike morphology at a 
moderate volume fraction. This observation is also in accord with that of Beta-C aged at 773 and $813 \mathrm{~K}^{(8)}$.

\section{Summary}

The crystallography and morphology of quenched and aged $\mathrm{Ti}-15 \mathrm{Mo}-5 \mathrm{Zr}$ and $\mathrm{Ti}-$ $15 \mathrm{Mo}-5 \mathrm{Zr}-3 \mathrm{Al}$ alloys were investigated by transmission electron microscopy. The results can be summarized as follows.

(1) There are two types of $\alpha$ phase which designated Type $1 \alpha$ and Type $2 \alpha$ as precipitates from the $\beta$ phase during aging. Type $1 \alpha$ obeys the well-known Burgers orientation. Type $2 \alpha$ with arced reflections in the electron diffraction patterns does not obey the Burgers orientation relation.

(2) The precipitation sequence $\beta \rightarrow \beta+$ Type $1 \alpha \rightarrow \beta+$ Type $2 \alpha$ was confirmed in the $\mathrm{Ti}-$ $15 \mathrm{Mo}-5 \mathrm{Zr}-3 \mathrm{Al}$ quenched from $1058 \mathrm{~K}$ and aged at 773 and $623 \mathrm{~K}$. The morphology of Type $2 \alpha$ which forms in this sequence is platelike.

(3) The transition $\omega \rightarrow$ Type $2 \alpha$ was observed in the $\mathrm{Ti}-15 \mathrm{Mo}-5 \mathrm{Zr}$ quenched from $1003 \mathrm{~K}$ and aged at $673 \mathrm{~K}$ for more than $6 \mathrm{ks}$. The morphology of Type $2 \alpha$ which forms in this sequence is like "rafts."

(4) The precipitation of either the $\omega$ phase or Type $2 \alpha$ phase with rafts morphology in a metastable $\beta$-titanium alloy results in complete macroscopic embrittlement, while the precipitation of Type $2 \alpha$ phase with platelets morphology shows considerable ductility at a moderate volume fraction.

(5) The $\omega$, Type $1 \alpha$ and Type $2 \alpha$ with platelets morphology were observed under the optimum heat-treatment condition for good tensile properties in the $\mathrm{Ti}-15 \mathrm{Mo}-5 \mathrm{Zr}$, while Type $1 \alpha$ and Type $2 \alpha$ with platelets morphology were observed in the $\mathrm{Ti}-15 \mathrm{Mo}-5 \mathrm{Zr}-3 \mathrm{Al}$.

\section{Acknowledgment}

This work was supported partly by Grantin-Aid for Scientific Research from the Ministry of Education, Japan.

\section{REFERENCES}

(1) S. Ohtani, M. Nishigaki: J. Japan Inst. Metals, 35 (1971), 97.

(2) S. Ohtani, M. Nishigaki and S. Tokuda: J. Japan Inst. Metals, 35 (1971), 378.

(3) S. Ohtani and M. Nishigaki: J. Japan Inst. Metals, 36 (1972), 90.

(4) S. Ohtani and M. Nishigaki: J. Japan Inst. Metals, 36 (1972), 346.

(5) S. Ohtani, T. Nishimura and M. Nishigaki: J. Japan Inst. Metals, 36 (1972), 1105.

(6) T. Nishimura, M. Nishigaki and S. Ohtani: J. Japan Inst. Metals, 40 (1976), 219.

(7) C. G. Rhodes and J. C. Williams: Met. Trans., 6A (1975), 2103.

(8) C. G. Rhodes and N. E. Paton: Met. Trans., 8A (1977), 1749.

(9) W. G. Burgers: Physica, 1 (1934), 561.

(10) R. A. Spurling: Met. Trans., 6A (1975), 1660.

(11) J. C. Williams and M. J. Blackburn: Trans. Met. Soc. AIME, 245 (1969), 2352.

(12) C. G. Rhodes: Metallogr., 2 (1969), 257.

(13) H. G. Paris, B. G. Lefevre and E. A. Starke, Jr.: Met. Trans., 7A (1976), 273.

(14) J. C. Williams, B. S. Hickman and H. L. Marcus: Met. Trans., 2 (1971), 1913. 